(C) 2016 IEEE. Personal use of this material is permitted. Permission from IEEE must be obtained for all other uses, in any current or future media, including reprinting/republishing this material for advertising or promotional purposes, creating new collective works, for resale or redistribution to servers or lists, or reuse of any copyrighted component of this work in other works. 


\title{
Position Paper: BE(Hons) Data Engineering
}

\author{
Robin Braun, Wayne Brookes, Zenon Chaczko \\ and Roger Hadgraft \\ School of Computing and Communications \\ University of Technology Sydney \\ Australia \\ Email: robin.braun@uts.edu.au
}

\section{INTRODUCTION}

This paper describes the UTS view of Data Engineering, and the degree program that has been created to educate Data Engineers. The document describes the guiding philosophies and the key ideas used in designing the program. The design of the program takes advantage of the 3rd, 4th and 5th shifts in engineering education[1]. Namely the shift to emphasizing design (problem solving) (3), the shift to applying education, learning, and socialbehavioral sciences research, and the shift to integrating information, computational, and communications technology in education. Mills and Treagast[2] question the relative value of Problem Based or Project Based learning in the Australian context. They quote a comparison of problem-based and project-based learning at tertiary level by Perrenet et al[3]. They noted that the similarities between the two strategies are that they are both based on self-direction and collaboration, and that they both have a multidisciplinary orientation. The differences that they noted included:

- Project tasks are closer to professional reality

- Project work is more directed to the application of knowledge

- Project-based learning is usually accompanied by subject courses (eg maths, physics etc. in engineering), whereas problem-based learning is not.

- Management of time and resources by the students as well as task and role differentiation is very important in project-based learning

- Self-direction is stronger in project work, compared with problem-based learning

With these comments in mind, this program is heavily Project Based in the Studio context. Sheppard et al[4] suggest that freshman students can benefit from "Design Experiences". This is a further approach taken in this program where design (creating solutions to problems) is introduced on day one.

\section{A. Professional drivers: IEEE}

The IEEE Technical Committee on Data Engineering[5] defines the discipline as follows:

Data Management Systems and Modern Hardware/Software Platforms, Data Models, Data Integration, Semantics and Data Quality Spatial, Temporal, Graph,
Scientific, Statistical and Multimedia Databases Data Mining, Data Warehousing, and OLAP Big Data, Streams and Clouds Information Management, Distribution, Mobility, and the WWW Data Security, Privacy and Trust Performance, Experiments, and Analysis of Data Systems

\section{B. Professional drivers: Engineers Australia}

Engineers Australia publish a set of graduate attributes for all engineering programs. This degree is designed to satisfy these, as well as specific attributes set by UTS.

\section{The UTS VIEW OF DATA ENGINEERING}

Data Engineering as defined at UTS is illustrated in Figure 1 on the following page. It can be thought of as a "circular" activity that starts with Data Gathering, then Processing and then Analysis and Decision Making. Finally the results are Presented and Acted upon. The process is repeated over and over again. All modern Data Centric systems can be represented in this way, and are pervasive in our society. Examples are Government Services, Banking systems, Transport Systems, Telco Operators, etc.

Underpinning all of this is both infrastructure and capability. This includes Computing, Storage and Transport infrastructure. Capability includes Computing, Data Analytics, Communications Engineering, Electronic Engineering, Software Engineering, Computer Systems Engineering, and others. UTS Data Engineers will bring an "Engineering" approach to all areas of Data Engineering.

An example of a fully integrated data centric system is the New South Wales Opal Card. It exhibits all aspects of a system as illustrated in Figure 1 on the next page. The Opal Card is illustrated in Figure 2 on page 3.

\section{The Driving PhILOSOPhIES}

\section{A. From "Accumulating Credit Points" to "Accumulating Abilities"}

\section{Belief}

That students do not know why and when they do what in their degree programs, and that this militates to them "falling back" on the "accumulating credit points" approach. 


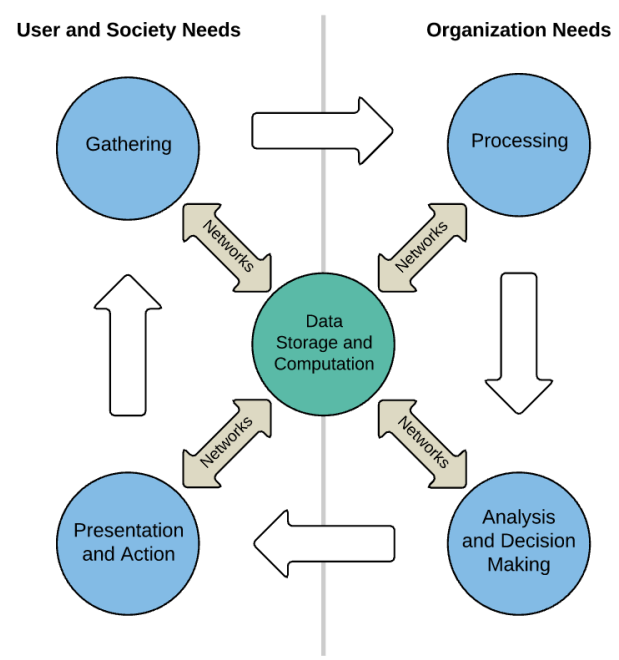

Figure 1. 4 Activities layout

\section{Consequently we believe that}

By changing the the program structure to the Stage/Studio approach described later, we can move students to an "accumulating abilities" orientation, and also help to "demystify" the engineering program.

\section{B. Unjamming the curriculum}

Belief

That current Engineering curricular are jammed, which leads to superficial knowledge and militates against deep understanding

\section{However we believe that}

Our graduates must achieve deep understanding and capability in at least one area

\section{Consequently we believe that}

We can achieve this by "unjamming" the curriculum through the sacrifice of "content" subjects to the creation of "studio" subjects.

\section{The balance between the Fundamentals and the Spe- cializations}

\section{Belief}

That there is a group of fundamental abilities that all Data Engineers should have

\section{However we also believe that}

All graduates should have in-depth mastery in at least one area (see Philosophy 2), and that the actual area is not important. It is only important that they have achieved mastery

\section{Consequently we believe that}

Having achieved mastery, students will have learned how to "do it".

\section{Student engagement}

Belief

That connection and engagement are extremely important drivers of student achievement and satisfaction

\section{Consequently we believe that}

The degree program must be structured to enhance a sense of connection and engagement in students, and that the notion of the Studio that will be a physical "home" for all Data Engineering students is a way to achieve this. Students must spend at least a few hours a week in the "Studio" and can return to it at any time.

\section{E. The central notion is the Outcomes.}

\section{Belief}

That Outcomes must be the Central Notion of the Degree, and that these must be simply stated with just 6 or 7 "headlines"

\section{Consequently we believe that}

As the Outcomes are so important, it is necessary for students to have a way of collecting and displaying the things they have done in order to achieve those outcomes, Hence we will be establishing an e-Portfolio system that will be a central component of the degree structure

\section{F. The importance of the Honours Project}

\section{Belief}

That the Honours Project is a vital capping of of the undergraduate program, and that it must signify a major accomplishment by the student.

\section{Consequently we believe that}

That students undertaking the project must have the special designation of "Honours Student", and that students may only enter this stage having achieved a particular point in their program (perhaps successful completion of the Applications Stage). We also believe that they be encouraged to undertake this stage exclusively of other activities

\section{G. Computer Programming}

Belief

That computer programming is a fundamental capability of all Data Engineers. We distinguish between two uses of programming languages

- Modeling (Matlab, R, Spreadsheets, etc.) and

- Application development (C, C++, Java, C\#, Python, etc.)

\section{Consequently}

We believe that all Data Engineers should be very proficient in at least one language from each group 


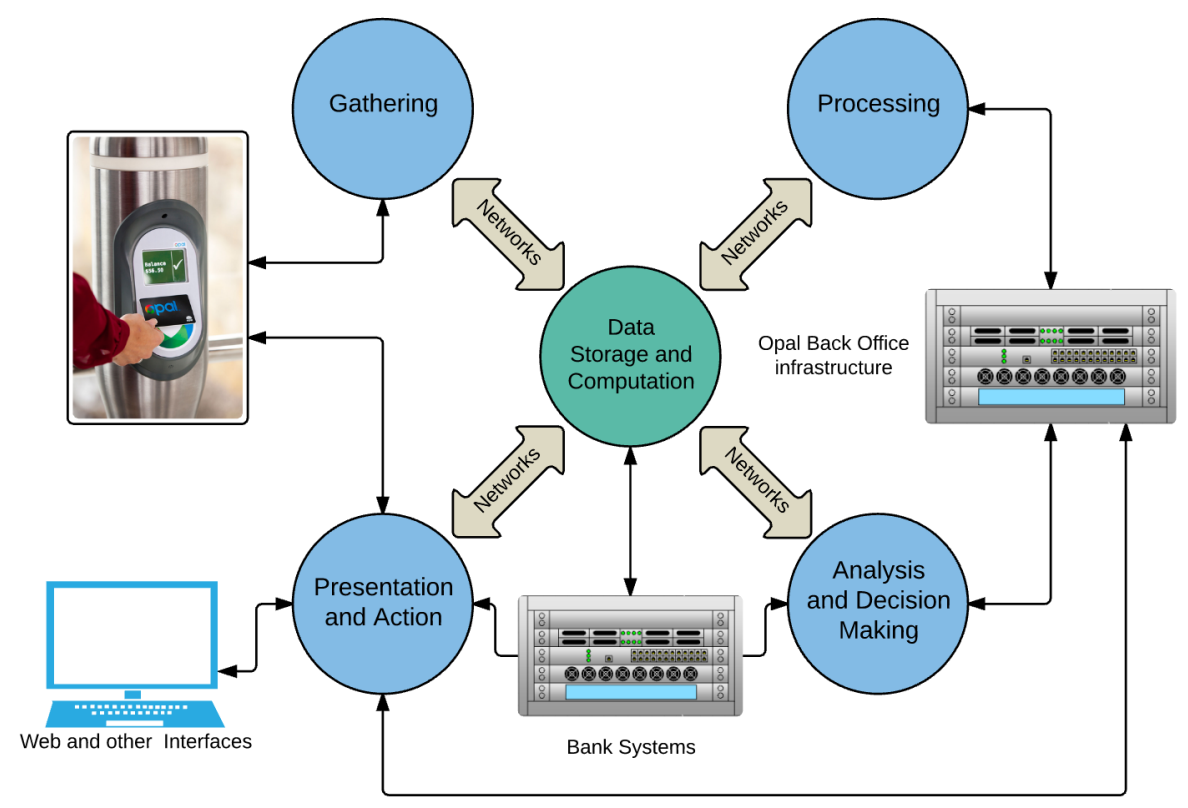

Figure 2. Opal Card

\section{H. Example that sets students thinking Abilities}

1) At the start of their First Year, students will enroll in group of fundamental subjects.

a) This is needed to "get them going".

b) However, early in their first semester they will be introduced to the "Stage" structure of the Program, and

c) will enroll into the Fundamentals Stage.

d) Then they work with their academic mentors to create a learning contract for that Stage that will include;

i) the outcomes required, and

ii) the activities and modules they will need to attain those Abilities

iii) The Studio specific activities

e) At this point, they will also get their e-Portfolio started which gets them into the notion of recording their Abilities and the things they did to achieve them

\section{STAGe Outcomes}

- Fundamentals Stage

1) Theoretical and Scientific Fundamentals

2) Data Engineering Fundamentals

- Applications Stage

1) Data Engineering Specialization (Sub-major)

- Professional Sequence

1) Professional Practice

2) Data Engineering Professional Ability

- Honours Project (Capstone)

1) Research and Innovation, and/or

2) Entrepreneurship and Business Development

\section{THE Key FeATURES}

The driving philosophies give rise to a set of "Key Features" of the program.

\section{A. The degree program that students see}

Fundamental to Philosophy 1 is that students are never presented with the traditional "grid" of Sessions and Subjects. Instead they are presented with "Outcomes/Stages" model as shown in Figure 4. This would help to create the notion amongst students that Abilities are Key, and that Credit Points are for administrative purposes.

\section{B. A curriculum unjammed}

The traditional engineering degree at UTS has 8 academic semesters of $24 \mathrm{cp}$ each. That is $192 \mathrm{cp}$. In this new structure, $36 \mathrm{cp}$ are removed from "content" orientated subjects and put in to "Studio" subjects. These subjects are not intended to be a way of exposing students to additional content. Rather they are a way of developing better competencies in fewer areas. For example, the Telecommunications Sub-Major in the BE ICT degree was made up of $36 \mathrm{cp}$ in two streams of content subjects. In this degree, the Sub-major is made up of a Fundamentals subject, 3 content based subjects and two Studio subjects.

\section{Views of the Program}

There are two "views" of the Program. The Student View that shows the Stages with the Abilities, and the Administration View that shows progression by session with credit points.

\section{The Learning Contract}

Stage management will be through the notion of a Learning Contract between the student and the Faculty. The contract will describe what abilities the student is required to achieve, and the means he or she have agreed to undertake to achieve those abilities. 


\section{The Stages as ENVISAged FOR DATA ENGINEERING}

\section{A. Stages are the way of locating Abilities}

Stages will be central to the new Program and represent an important innovation. They are the means by which the Abilities are grouped, and attained by the student.

1) Fundamentals Stage : The Fundamentals Stage will provide a "First Spiral" through all aspects of Data Engineering as illustrated later. The student will use this stage of grouping his or her Fundamental Abilities that are needed to practice in Data Engineering.

2) Applications Stage: The Applications Stage provides a "Second Spiral" through Data Engineering with emphasis on a particular Application Area.

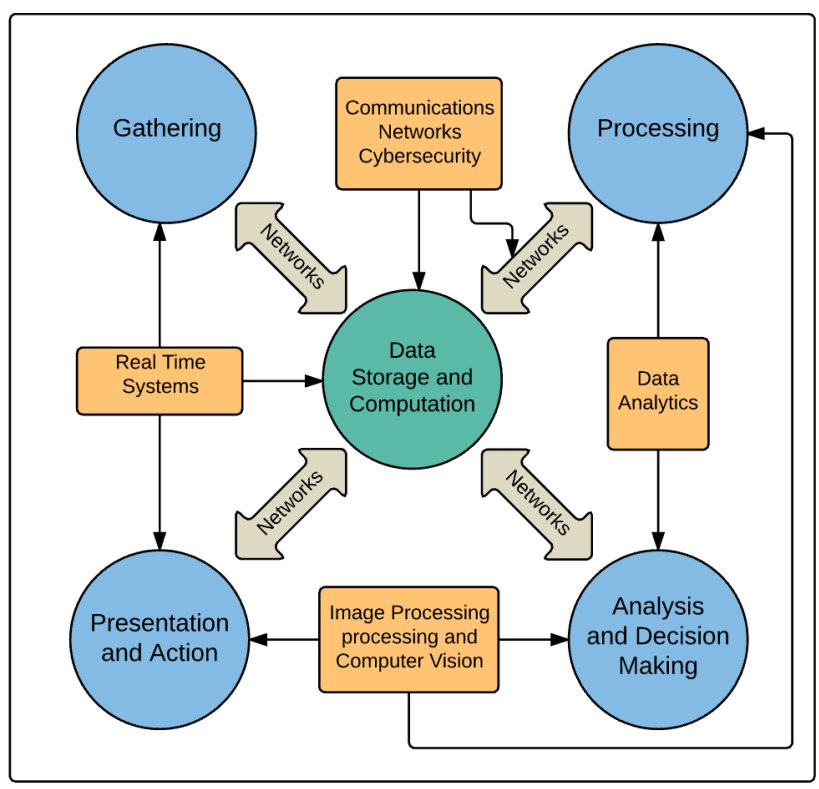

Figure 3. Applications "Spiral"

3) Professional Sequence : This sequence of activities will be known as the Professional Sequence as it does not signify a particular "Stage" of the degree program. Rather, it continues throughout the degree in parallel with the other stages. It provides a "Third Spiral" through the Professional Practice of Data Engineering

4) Honours Stage: This is the Stage during which the student undertakes the Honours Project. This is where the students develops their Abilities in one or more of the areas of Research and Innovation, Engineering Design and Application and/or Entrepreneurship and Business Development.

\section{B. Stage Structure}

The Degree Program is illustrated in Figure 4 on the next page. Student will progress through the Stages as follows:

- On entry to the program they will be known as Fundamental Stage Students

- Once they progress to the Applications Stage they will be known as Applications Stage Students
- Professional Development continues throughout their degree program and does not signify a particular stage

- On entry into the Honours Stage they will be know as Honours Students

\section{The Learning Contract}

Stage management will be through the notion of a Learning Contract

- For each of the Stages, the student will have a Learning Contract

- This will be created by an iterative process in conjunction with their Academic Mentors

- It will have the ability to "re-visit" its terms if these change

- A possible management system is shown in the next slide.

A workflow for managing the Learning Contract is shown in Figure 5 on the following page

\section{Studios AND HOW They RELATE to The Stages}

\section{A. Stages and their Studios}

Each of the stages has a Studio component that is designed to enhance the learning and the achievement of the outcomes for that Stage. Studios are structured as $6 \mathrm{cp}$ modules. They will include a variety of activities and be "team" coordinated. Activities will be Project and Problem based, and may undertaken by teams or individuals.

\section{B. Studio Activities}

1) Associated conventional subjects (both prerequisite and co-requisite).

2) A composite class approach

3) Problem/Project based

4) Team and individual projects

5) Nano modules for particular technical skills, including automated threshold testing

6) Self/team-directed

\section{Studios will be team facilitated}

The Teams will consist of general and specialist academics and researchers, research students, professional staff, visitors, industry representatives, library and other UTS staff. The Academics will mostly be drawn from the subjects most closely associated with that Stage. They may include other students. Some students will be invited to extend their involvement in particular Studios to act as leaders. 


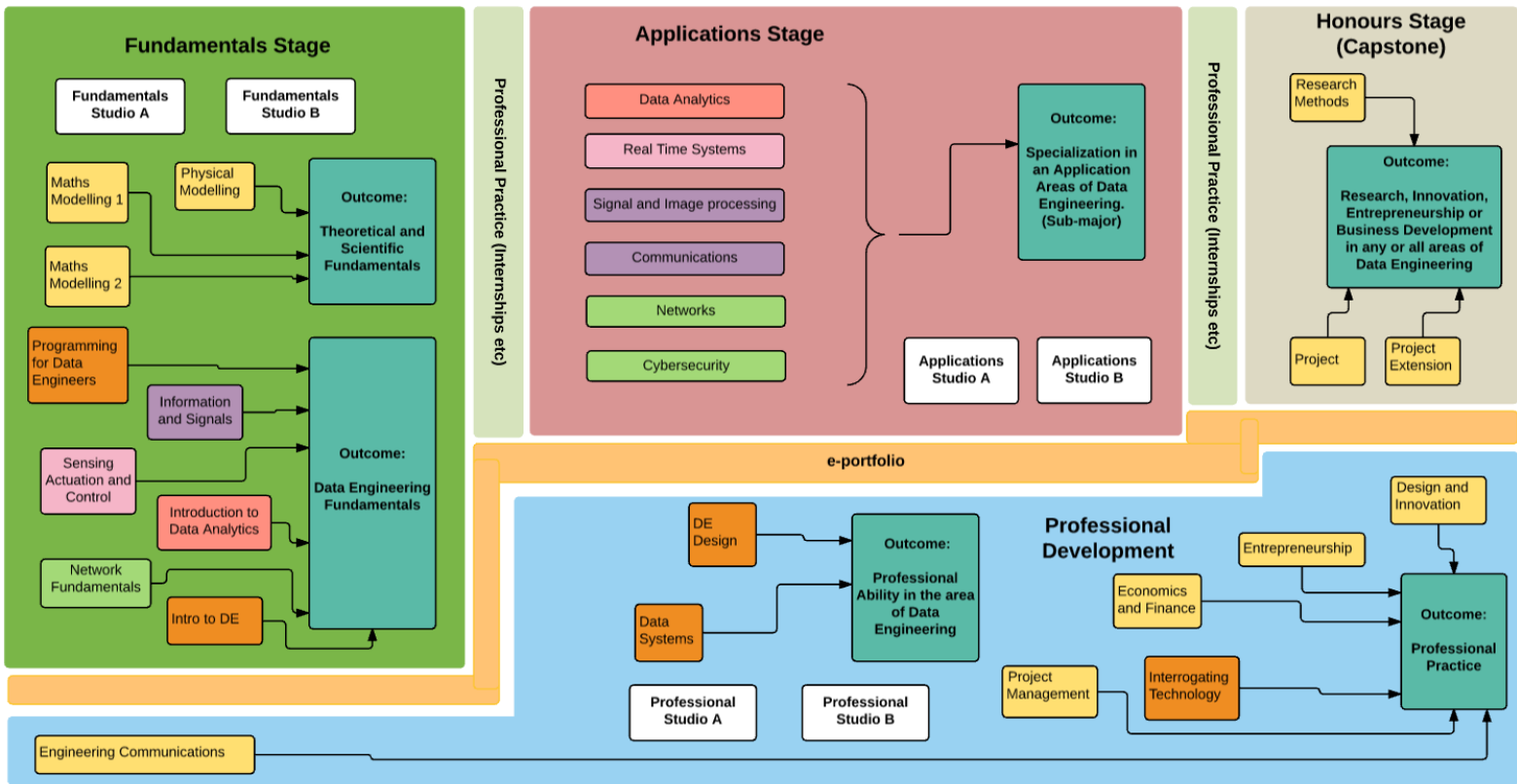

Free Electives

Figure 4. The new Stage Based program

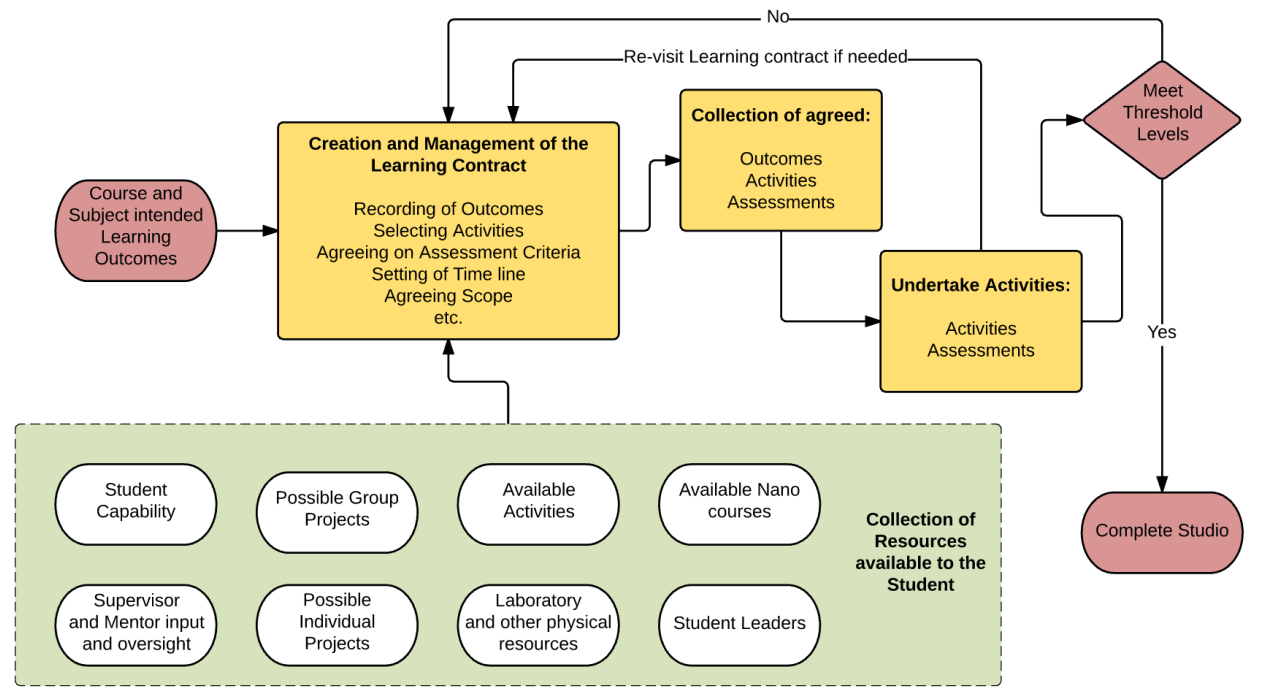

Figure 5. Studio Management

\section{CONCLUSION}

We have designed and implemented a new program for the new profession of Data Engineering. We have based the design on a set of driving philosophies, which in turn give rise to a number of Key Ideas. These can be summarized as follows:

1) Students are never presented with the traditional "grid" of Sessions and Subjects. Instead they are presented with an "Outcomes/Stages" model.

2) Stages will be central to the new Program and represent an important innovation. They are the means by which the Abilities are grouped, and attained by the student.

3) The Fundamentals Stage will provide a "First Spiral" through all aspects of Data Engineering as illustrated later. The student will use this stage for grouping his or her Fundamental Abilities.

4) The Applications Stage provides a "Second Spiral" through Data Engineering with emphasis on a particular Application Area.

5) The sequence of activities known as the Professional Sequence as it does not signify a particular "Stage". Rather, it continues throughout the degree in parallel with the other stages. It provides a "Third Spiral" through the Professional Practice of Data Engineering

6) The Stage during which the student undertakes the Honours Project. This is where the students develops their Abilities in one or more of the areas of Research and Innovation, Engineering Design and Application and/or Entrepreneurship and Business Development. 
The traditional engineering degree at UTS has 8 academic semesters of $24 \mathrm{cp}$ each. That is $192 \mathrm{cp}$. In this new structure, $36 \mathrm{cp}$ are removed from "content" orientated subjects and put in to "Studio" subjects.

\section{REFERENCES}

[1] J. E. Froyd, P. C. Wankat, and K. a. Smith, "Five major shifts in 100 years of engineering education," Proceedings of the IEEE, vol. 100, no. SPL CONTENT, pp. 1344-1360, 2012.

[2] J. E. Mills, D. F. Treagust, and Others, "Engineering education - Is problem-based or project-based learning the answer," Australasian Journal of Engineering Education, vol. 3, no. 2, pp. 2-16, 2003.

[3] J. Perrenet, P. Bouhuijs, and J. Smits, "The suitability of problembased learning for engineering education: theory and practice," Teaching in higher education, vol. 5, no. 3, pp. 345-358, 2000.

[4] S. Sheppard and R. Jennison, "Freshman engineering design experiences and organizational framework," International Journal of Engineering Education, vol. 13, pp. 190-197, 1997.

[5] I. Committee, "Technical Committee on Data Engineering," http://tab.computer.org/tcde/, 2016, [Online; accessed 18-July-2016.

[6] _ " "Technical Committee on Computer Communications," http://tccc.committees.comsoc.org/, 2016, [Online; accessed 18July-2016.

[7] K. A. Smith, "Cooperative learning: Making groupwork work," New directions for teaching and learning, vol. 1996, no. 67, pp. 71-82, 1996.

[8] C. L. Pearson and C. J. Beasley, "Reducing learning barriers amongst international students: A longitudinal developmental study," The Australian Educational Researcher, vol. 23, no. 2, pp. 79-96, 1996.

[9] K. A. Smith, D. W. Johnson, and R. T. Johnson, "The use of cooperative learning groups in engineering education," in Proceedings Eleventh Annual Frontiers in Education Conference, Rapid City, SD, Washington: IEEE/ASEE, 1981, pp. 26-32.

[10] J. Bordogna, E. Fromm, and E. W. Ernst, "Engineering education: Innovation through integration," Journal of Engineering Education, vol. 82, no. 1, pp. 3-8, 1993.

[11] D. A. Rosenthal, J. Russell, and G. Thomson, "Social connectedness among international students at an Australian university," Social indicators research, vol. 84, no. 1, pp. 71-82, 2007.

[12] R. M. Felder, D. R. Woods, J. E. Stice, and A. Rugarcia, "The future of engineering education II. Teaching methods that work," Chemical Engineering Education, vol. 34, no. 1, pp. 26-39, 2000.

[13] D. W. Johnson, R. T. Johnson, and K. A. Smith, "Cooperative learning returns to college what evidence is there that it works?" Change: the magazine of higher learning, vol. 30, no. 4, pp. 26-35, 1998.

[14] H. J. Passow, "Which ABET competencies do engineering graduates find most important in their work?" Journal of Engineering Education, vol. 101, no. 1, p. 95, 2012

[15] H. A. Hadim and S. K. Esche, "Enhancing the engineering curriculum through project-based learning," in Frontiers in Education 2002. FIE 2002. 32nd Annual, vol. 2. IEEE, 2002, pp. F3F-1.

[16] A. J. Dutson, R. H. Todd, S. P. Magleby, and C. D. Sorensen, "A Review of Literature on Teaching Engineering Design Through Project-Oriented Capstone Courses," Journal of Engineering Education, vol. 86, no. 1, pp. 17-28, 1997.

[17] V. Wilczynski and S. M. Douglas, "Integrating design across the engineering curriculum: A report from the trenches," Journal of Engineering Education, vol. 84, no. 3, pp. 235-240, 1995.

[18] I. I. Phase and Others, Educating the engineer of 2020: Adapting engineering education to the new century. National Academies Press, 2005.

[19] B. E. Seely, "The other re-engineering of engineering education, 1900-1965," Journal of Engineering Education, vol. 88, no. 3, p. $285,1999$.

[20] B. M. Olds and R. L. Miller, "The effect of a first-year integrated engineering curriculum on graduation rates and student satisfaction: A longitudinal study," Journal of Engineering Education, vol. 93 , no. 1, p. 23, 2004.

[21] D. W. Johnson and R. T. Johnson, "Structuring Learning Goals To Meet the Goals of," Engineering Education, 1981.

[22] K. A. Smith, S. D. Sheppard, D. W. Johnson, and R. T. Johnson, "Pedagogies of engagement: Classroom-based practices," Journal of Engineering Education, vol. 94, no. 1, pp. 87-101, 2005.
[23] S. L. Toral, M. d. R. Martinez-Torres, F. Barrero, S. Gallardo, and M. J. Duran, "An electronic engineering curriculum design based on concept-mapping techniques," International Journal of Technology and Design Education, vol. 17, no. 3, pp. 341-356, 2007.

[24] K. A. Smith, "Cooperative learning: Effective teamwork for engineering classrooms," in Frontiers in Education Conference. IEEE 1995, pp. 12-13.

[25] R. G. Carter, "Engineering curriculum design," IEE Proceedings APhysical Science, Measurement and Instrumentation, Management and Education-Reviews, vol. 131, no. 9, pp. 678-683, 1984.

[26] D. L. Evans, G. C. Beakley, P. E. Crouch, and G. T. Yamaguchi, "Attributes of engineering graduates and their impact on curriculum design," Journal of Engineering Education, vol. 82, no. 4, pp. 203211, 1993.

[27] F. C. Berry, P. S. DiPiazza, and S. L. Sauer, "The future of electrical and computer engineering education," IEEE Transactions on Education, vol. 46, no. 4, pp. 467-476, 2003.

[28] J. Allen, S. B. Robbins, A. Casillas, and I.-S. Oh, "Third-year college retention and transfer: Effects of academic performance, motivation, and social connectedness," Research in Higher Education, vol. 49, no. 7, pp. 647-664, 2008. 